\title{
DIE VRYBURGERS VAN 1657. Húlle was die eintlike Volksplanters
}

Die driehonderdjarige herdenking van die instelling van die eerste vryburgers op 21 Februarie 1657 kan beslis nie onopgemerk verbygegaan word nie. Dit was 'n gebeurtenis wat vir die geskiedenis van Suid-Afrika en die van die blanke beskawing in hierdie land van die allergrootste betekenis was; maar dit is ook een van die baie gebeurtenisse in ons geskiedenis wat onteenseglik toon dat die geskiedenis beslis nie deur mense gemaak word nie, maar dat agter die geskiedenis 'n Hoërhand is wat alles rig en bestier.

Toe ons vyf jaar gelede oor die hele land Van Riebeeckfeeste georganiseer en gevier het, was die sentrale tema "die bou van 'n nasie." Van alle kante, in woord en geskrif, is Van Riebeeck geloof as die stigter van die volksplanting aan die Kaap, wat wel waar is mits hier- 
die stigtersdaad net nie aan sy aankoms aan die Kaap gekoppel word nie. In April 1652 was hy en diegene wat saam met hom gekom het beslis nog geen volksplanters nie, want een en almal was slegs amptenare van die Kompanjie wat na die suidpunt van Afrika gestuur is, slegs met een doel: om 'n verversingspos in die lewe te roep. In die instruksies aan Van Riebeeck word niks gelees van kolonisasie nie; trouens, kort voor sy vertrek na die Kaap het die Bewindhebbers nog aan hom opdrag gegee om geen ander Europese volk te verhinder wat hulle miskien ook aan die suidpunt van Afrika sou wou vestig nie. Inderda:ad was kolonisasie geen doel van die Kompanjie, wat by uitstek 'n handelsmaatskappy was, nie en waar hulle nog in die Ooste gekoloniseer het, was dit alleen noodgedwonge en in belang en ter beskerming van hulle handelsonderneminge. Kolonisasie aan die suidpunt van Afrika, wat op 21 Februarie 1657 met die instelling van die eerste vryburgers ' $n$ aanvang geneem het, was dan ook rie in die Kompanjiesprogram ingesluit nie, maar het as 'n praktiese noodwendigheid gekom en wel ten gevolge van bepaalde faktore. In hierdie faktore het die persoon van J.an van Riebeeck 'n groot rol gespeel. Daarom wil ons hierdie faktore kortliks in oënskou neem, met die persoon van Van Riebeeck as sentrum.

Van Riebeeck, 'n baie bekwame man, wat vroeër 'n hoë betrekking in Kompanjiesdiens in die Ooste beklee het, maar wat uit die diens ontslaan is omdat hy hom aan privaathandel-'n onvergeeflike oortreding in die oë van die Kompanjie--skuldig gemaak het, het in die besluit van die Kompanjie om 'n verversingspos aan die Kaap te stig die geleentheid gesien om weer in hierdie matskappy se diens terug te keer. Toe Nicolaas Proot om een of ander rede nie as hoof van die groep wat na die Kaap sou gaan aangestel is nie, het Van Riebeeck die geleentheid te baat geneem om sy dienste vir die pos eerbiediglik aan die Kompanjie aan te bied. Hierdie aanbod is aanvaar. Dié aanbod het egter nie net met die blote verkryging van 'n betrekking in verband gestaan nie, want Van Riebeeck eindig sy kommentaar op die memorandum wat Janszen en Proot vir die Kompanjie opgestel het, met die bede dat God aan hom versigtigheid en verstand mog verleen om die Kompanjie só te mag dien dat hy in rang verhoog sou word en nadat hy sake aan die Kaap aan die gang sou hê, vir belangriger werk in Indië gebruik sou word, sodat hy aldaar ,meerder preuven van capitaler diensten' 'sou kon lewer. 
Van Riebeeck se kop het na die Ooste toe gestaan; en toe hy op 5 April 1657 in sy Dagverhaal aangeteken het: „Omtrent 5 glasen in de namiddaghwacht sagen wij, Gode loff, 't lant van Cabo de Boä Esperance, namentlijck den Taffelbergh ....", was hierdie land wat hy gesien het nie vir hom (en diegene wat saam met hom was) 'n nuwe vaderland nie, maar slegs 'n tydelike standplaas-'n springklip na die Ooste-waar hy nie van plan was om lank te bly nie. Laasgenoemde bewering word gestaaf o.a. deur die persoonlike brief wat hy op 18 April, twaalf dae na sy aankoms aan die Kaap, saam met die Salamander aan die Bewindhebbers gestuur het waarin hy versoek het om van dié plek verlos te word.

Wat Van Riebeeck se planne ook al mog gewees het, en hoe hy ook al pogings in die werk gestel het om so gou as moontlik van die Kaap weg te kom, was die verloop van die geskiedenis anders bepaal en moes Van Riebeeck tien vir hom lange jare zan die Kaap vertoef om die bepaalde historiese taak, waarvoor hy voorbestem was, te verrig. Dit was 'n taak waardeur hy o.a. die vader van die instelling van die vryburgers sou word, 'n taak wat, sonder dat hy daarna gestreef of selfs bewus daarvan was, aan hom 'n ereplek in die geskiedenis van SuidAfrika sou besorg, nl. die van stigter van die volksplanting aan die Kaap.

Van Riebeeck het geweet dat hy nie op bevordering na die Ooste kon reken voordat die Kaapse verversingspos aan sy doel beantwoord nie. Gevolglik het die mislukte en swak oeste gedurende die eerste jare, veral ten opsigte van koring, vir die Kommandeur niks anders as bittere teleurstelling ingehou nie. Hierdie omstandighede het hom net verder versterk in die gedagte wat hy reeds vanaf sy aankoms aan die Kaap gekoester en wat hy onder datum 27 April 1657 in sy Dagverhaal aangeteken het, nl. dat in die omgewing van Tafelbaai goeie grond en gunstige toestande vir die verbouing van graan was ,alser maer volck die onkostegenoech toe was, daer eenige g'troude Chinesen ende andere vrije mardijckers ofte oock wel Nederlanders, toe verijsschen ende onder seeckere conditien vergunt souden connen worden eenige parcken lants te beslaen." Dit was die eerste keer dat van die moontlikheid van Nederlandse vryburgers as landbouers aan die Kaap melding gemaak is.

Van Riebeeck was oortuig dat die landbou veel beter behartig sou kon word as dit in die hande van vryliefde gegee word as om dit met 
die hulp van 'n klompie betaalde amptenare te beoefen. Maar wat sou die Kompanjie van so 'n plan dink? Hierdie handelsliggaam het tog immers nie in kolonisasie belang gestel nie terwyl Van Riebeeck se plan juis kolonisasie ingehou het, sy dit dan ook op klein skaal. Intussen sou Van Riebeeck maar eers die verwyte van Here XVII in verband met die onkoste wat die Kaap meegebring het vanweë die invoer van veral rys as gevolg van swak graanoeste, ens. moes verdra. Hy sou eers die nodige proefnemings uitvoer sodat hy grond onder sy voete kon hê wanneer hy uiteindelik sy rewolusionëre voorstel met betrekking tot die Kaap aan sy lasgewers voorlê.

Terwyl hy nog gepeins het oor hoe en wanneer hy sy voorstel sou doen, moes dit vir Van Riebeeck 'n groot verligting gewees het toe hy vroeg in 1655 'n brief, d.d. 6 Oktober 1654, van die Bewindhebbers ontvang het. Hulle skrywe dat 'n sekere skipper, David Claes: Swaegh, wat verskeie kere by die Kiap aangedoen het, aan hulle 'n gedagte voorgelê het na aanleiding van 'n besoek wat hy (Swaegh) saam met Van Riebeeck aan Houtbaai gebring het. Swaegh het vertel dat vanaf die baai „een valije soude beginnen sich streckende achter den Tafelbergh om, seer bequaem nae sijn oordeel om ter culture te brengen, en rijs, coren, an andere vruchten aldaer te teelen ... en waertoe hij meent dat eenige huijsgesinnen van hier seer dienstich souden wesen." Eni dan volg die uitnodiging wat vir Van Riebeeck die weg na Here XVII oopgemaak het. HIere XVII wou geen beslissing aangaande hierdie saak gee voordat hulle eers Van Riebeeck se opinie en advies ingewin het nie; derhalwe versoek hulle hom: „om ons een claer en pertinent bericht daer van te cunnen toesenden, maeckende soo doenlijck van alles een caerte.'

Op 28 April 1655 het Van Riebeeck geantwoord en meteen van die geleentheid gebruik gemaak om sy planne en voorstelle in extenso aan die Bewindhebbers mee te deel. Hy stel dit duidelik dat hy self lankal aan die beoefening van die landbou deur vryliede gedink het maar dat hy nooit gedink het „dat UEd. aan dese plaetse tot eenige colonie souden inclineren" aangesien hy nog altyd onder die indruk was dat die Kompanjie se oogmerk met die Kaap niks anders was nie as maar net "om genoeghsame verversinge voor UEd: aencomende scheepen aen te focken." Uit hulle brief sien hy egter nou dat hulle "tot colonie te stabileren schijnen gesint te wesen" en om daardie rede "sullen wij ons gevoelen daervan verckaeren, namentlijck dat om vee ende coren hier 
aan te focken op verscheijdene plaetsen cans genogh is ..." Met betrekking tot die Bewindhebbers se vraag aangaande die moontlikhede van die Houtbaaivallei, meen hy dat dit nie nodig is om so ver van die fort af te gaan nie, omdat binne twee tot vier myl van die fort af, nog ,aen dese cont" van die berg, genoeg grond en geleentheid was vir 1000 huisgesinne om 'n bestaan te maak.

Van Riebeeck het egter ook nog verder gegaan as om net 'n blote antwoord op Here XVII se vraag te gee, en in hierdie antwoord, wat ek graag taamlik breedvoerig hier wil weergee, het hy getoon dat hy inderdaad ook 'n man van visie was. Hy was maar taamlik twyfelagtig of die vryliede almal geneë sou wees om „behoorlijcke naerstighheijt aan te wenden tot de culture" aangesien die ervaring in ander Kompanjiesbesittinge veelal geleer het dat die meeste sodanige vryliede maar net een doel voor oë het naamlik „om metter haest de saecken vol te rapen, ten welcken eijnde het dan liever dadelijck opeen tappen ende snappen setten ') tot groote debauche ${ }^{2}$ ) van 't volcq." Van Riebeeck het ook nie die verwagting gekoester dat iemand sou besluit om na die Ka:up te kom as juis arm en behoeftige huisgesinne "van cleijne reputatie" nie. Sodanige mense sou nie juis veel omgee hoe hulle hulle geld bekom nie en sou derhalwe die maklikste metodes daartoe aanwend, naamlik om 'n kantien aan te hou. Indien aan die Kaap 'n kolonie tot stand sou kom, sou hierdie tipe persone aan die ander kant egter ook nie vermy kon word nie. Daarom gee hy aan die hand dat, indien tot kolonisasie oorgegaan sou word die Kompanjie middels beskikbaar moes stel vir die onderhoud van vryliede totdat hulle in staat sou wees om hulleself uit hulle boerderye te onderhou. Daarsonder sou niemand bereid wees om hom na so 'n woeste en wilde land te begewe nie. Daarom is hy van opinie dat „d'E. Comp. haer vooreerst souden moeten getroosten alle soodanige huijsgesinne soo lange te spijsen ende de cost ende huijsvestingh te geven off laten maecken tot sij haere landerijen tot eenige bequaemheijdt hadde gebracht, die se dan oock voor simmige jaren souden dienen sonder belastinge te besitten om na verloop van tijt eerste met sulcke tributen te beswaren als na de gelegentheijt mochte bevonden worden te vereijsschen."

Om te voorkom dat vryliede, soos in die Ooste dikwels ervaar is, weer na hulle vaderland terugkeer sodra hulle hulle sakke gevul het,

1) 'n kantien aanhou.

') losbandigheid; demoralisasie. 
wat sou meebring dat slegs die behoeftiges in die kolonie sou agterbly, het Van Riebeeck voorgestel dat alleen diegene wat bereid sou wees om te onderneem om self minstens tien jaar lank in die kolonie te bly, en hulle kinders twintig jaar (wat sou meebring dat die ouers ook langer bly) as vryliede te aanvaar. Sulke vryliede sou dan mettertyd van Holland gespeen word en van die Kaap hulle vaderland maak. Dit sou tot noodwendige gevolg hê dat die vryliede meer ywer ten opsigte van die bewerking en verbetering van hulle plase aan die dag sou lê en uiteindelik sou die Kompanjie sy aanvanklike onkoste weer kon terug kry deur die heffing van belastings wanneer hierdie liede goed gevestig is, terwyl ook inkomste verkry kon word uit die verkoop van Europese en Oosterse handelsware aan die vryliede.

Sodanige vryliede moes dan verplig word om hulle produkte alleen aan die Kompanjie te verkoop vir geld of te verruil vir sulke ware as w:at hulle sou benodig. Hy het dit goedgedink dat die Kompanjie „van alles meester blijft" en dat die vryliede dus nie toegelaat moes word om met enigiemand anders handel te dryf nie as net met die Kompanjie of met persone en liggame wat eers vooraf deur die Kompanjie goedgekeur word. Om sukses vir die vryliede te verseker moes die Kompanjie hom verder van aktiewe landboubeoefening weerhou terwyl die vryliede ook slagvee aan die Kompanjie moes lewer. Om hierdie mense so gou as moontlik op die been te bring moes slawearbeid so gou doenlik aan hulle voorsien word. Hierdie slawe moes dan op krediet aan hulle verkoop word en betaling moes geskied sodra hulle daartoe in staat was.

En dan sluit hy sy pleidooi af: ,als UEd: haar d'oncosten dan gelieven te getroosten om als voorseijt de vrije huijsgesinnen vooreerst uijt de handt te onderhouden soo soudet misschien wel mogen gaan sonder dat wij behoeven na 'nt hout baijcken te loopen, sijnde aen dese binnen cant bequaem landt genoegh ter culture ende oock goede gelegentheijdt om haar voor deese inwoonders te verseeckeren." Aangesien niemand sommer na 'n ,,soodanigen wilt ende woesten landt op ijdele hoope comen" sal en aangesien die stuur van vryliede vanuit die moederland baie onkoste sou meebring, beveel Van Riebeeck aan dat eers met drie of vier huisgesinne, wat hulle alreeds aan die Kaap bevind en dus met die omstandighede bekend is, proefnemings gedoen moes word.

Van Riebeeck het sy saak goed gestel-só goed dat Here XVII op 30 Oktober 1655 geantwoord het dat hulle van sy uiteensetting kennis 
geneem het en dat hulle dit goedgevind het „UI. te authoriseren dat Ul. sullen vermoogen die geenen die door ervarentheijt kennisse van de gelekentheijt van de landen hebben bekomen en mette culture aenqueeckinge van beestiael als anders haer selven buijten last van de Comp. sullen cunnen erneren des versoeckende in vrijdom te stellen mits dat se sullen gehouden sijn den tijt van thien jaren daer te lande te blijven en d-at haer daer en boven op haer versoeck onder gelijck verbant hare vrouwen en kinderen sullen toegesonden worden des dat deselve kinderen mitgaders die se verder souden comen te procreeren daer te lande sullen moeten verblijven den tijt van twintigh jaren te reeckenen van haer aencomste off geboorte aldaer resp.-e mits dat se verder subject sullen wesen alle sood: ordonnantien als bij de Comp. uit regarde van de vrije luijden in India al bereijts sijn gemaeckt souden mogen worden."

Vir Van Riebeeck was dit seker 'n groot verrassing, maar blykbaar het hy aan die spreuk geglo dat versigtigheid die moeder van die wysheid is. Mens sou verwag dat hy die geleentheid onmiddellik met alle mag sou aangryp, maar hy was nie van plan om oorhaastig te werk te ga:un en dalk die hele saak te bederf nie. Hy wou seker mak dat die onderneming sou slaag, want hy het nog steeds promosie na die Ooste begeer. Mislukking van die vryburgersonderneming aan die Kaap sou die stadium waarop die Kaap selfonderhoudend sou wees net langer uitstel en noodwendig sou dit sy vertrek na die Ooste ook vertraag. Alles moes eers deeglik beplan en uitgetoets word.

Teen Oktober 1656 het Here XVII nog geen berig van Van Riebeeck aangaande vryburgers ontvang nie en het hulle dit vertolk as sou daar nog geen persone gewees het wat hulle as vryburgers aangebied het nie. Derhalwe skrywe hulle op 12 Oktober aan Van Riebeeck: „Uijt Ul. schrijvens bevinden wij niet dat haer voor als noch eenige ge-

negen getoont hebben om haer vrijdom te hebben, en haer daer als vrije luijden te erneren, en tot dien eijnde hare vrouwen en kinderen van hier 't ontbieden; de luijden moeten soo groote voordelen daer nog niet in sien: watter vorder sal willen vallen sullen wij moeten afwachten, soo der eenige haer tot vrijlieden begeven, sullen Ul. weldoen haer de hant wat te bieden om des te beter te cunnen bestaen, en andre daertoe oock te meer te animeren ...."

Wat wel die geval was, is dat Van Riebeeck nog nie so 'n aanbod aan Kompanjiesdienare aan die Kaap gedoen het nie, omdat hy nog 
steeds besig was om die hele saak grondig te beplan, o.a. waar aan die vryliede die beste gronde gegee kon word, hoe hulle die beste gehelp kon word, ens. In sy Dagverhaal makk hy telkens melding van nuwe grond wat persoonlik deur hom uitgesoek is en waarop allerlei eksperimente met verskillende gewasse uitgevoer is. Teen Desember 1956 was hy tevrede met sy proefnemings en het hy die tyd en geleentheid ryp geag om by die amptenare propaganda vir die saak van die vryburgerskap te maak. Op 5 Desember teken hy naamlik in sy Dagverhaal aan: „'s morgens fray weer ende wint als vooren. Is den Commandeur eens na 't corenlandt ende bos gereden omdat (om?) over verscheyden saken van gewoonte ' $t$ oogh te Iaten gaen, ten eijnde de luijden te meer in haren ijver overal mochten gehouden worden, latende met hem meteenen medegaen op een wagen alle de Nederlantsche vrouwe van de Caep, om oock dselve eens wat vermaeck aen dese plaetse aen te doen, met dewelcke dan een goet stuck 't landt is ingereeden, alsmede in 't bos, etc., tot desselver plaisier, bijsonderlijk te scheppen in den wasdom van het coren, tabacq, Turxe en andre boonen aen 't ronde doornbosjen, soo schoon ende treffelijck staende off 't selffs in 't vaderlandt was, gelijck vooren dickmael aengetogen."

Presies wanner Van Riebeeck die kwessie van vryburgschap aan die amptenare gestel het, is nie bekend nie. Op 19 Februarie 1657 het die Kommandeur egter, volgens 'n aantekening in die Dagverhaal, uitgery „3 à 4 mijlen wegh in de vlacte acgter de Taeffel- ende andere bergen om de laenderijen aldaer noch wat nader aff te speculeeren, neffens een bequaeme plaetse om een redout te stellen tot bewaringe ende behoorlijcke diffentie van de cultiveren landen, waertoe verscheijden persoonen haer presenteerden in vrijdom te begeven onder soodanige billicke conditien als waermede d'E. Compagnie dienste geschieden enden oock haer tot behoudenisse strecken conde."

Op 20 Februarie moes die Kommandeur dieselfde gebied weer besoek om nog ander persone wat om vryburgerskap aansoek gedoen het, die geleentheid te gee om ook hulle grond uit te soek.

En dan eindelik! 21 Februarie 1657 moes vir Van Riebeeck 'n groot en wonderlike dag gewees het. 'n Groot ideaal was vervul toe hy aan die eerste nege burgers, gekies uit meer wat hulle aangebied het, hulle vry-en grondbriewe kon uitreik. Daarmee het hy voorwaar die stigter van die volksplanting aan die Kaap geword. Maar Van 
Riebeeck sou dit nooit kon reggekry het, as dit nie vir hierdie nege manne was, wat hulle bereid verklaar het om hulle geheel en al an die bodem van Suid-Afrika te verbind en om hierdie land as hulle

vaderland aan te neem nie. Daarin lê vir ons die groot betekenis van hierdie hele vryburgergeskiedenis; daarom dink ons vanjaar, na driehonderd jaar nog in dankbaarheid terug aan hierdie eerste volksplanters.

Maar wie was hierdie manne? 'n Oorsig soos hierdie kan nie volledig wees sonder om hulle aan die leser voor te stel nie, en beter kan ek dit nie doen nie as wat Van Riebeeck dit self gedoen het: „Harmen Remajenne van Ceulen, bosschieter; Jan Maertensz. de Wacht van Vreelandt, dito; Jan van Passel van Geel in Brabant, soldaet, dat oock een broeuwer ende brandewijnbrander is; Warnaer Cornelisz. van Nunspeet, bootgesel; Roeloff Jansz. van Dalen, soldaet; . . . . . Steven Jansz. van Wageningen, bootsgesel, geverseert in de tabacqplanterije; Hendrick Elbertz. van Ossenbrugge, adelborst; Otto Jansz. van Vreede, soldaet; Jacob Cornelisz. van Rosendael, dito; ..." Dit is hierdie manne wie se name in die annale van ons geskiedenis as die eerste boere in Suid-Afrika geskrywe staan; dit is hierdie manne wat die weg gebaan het vir die perminente bewoning van Suid-Afrika.

P.U. vir C.H.O.

J. S. DU PLESSIS. 